\title{
Prototype Spatio-temporal Predictive System of pest development of the codling moth, Cydia pomonella, in Kazakhstan
}

\author{
A. Afonin ${ }^{1,}{ }^{*}$, B. Kopzhassarov², E. Milyutina', E. Kazakov ${ }^{3,4}$, A. Sarbassova ${ }^{2}$ \\ and A. Seisenova ${ }^{2}$
}

Summary A prototype for pest development stages forecasting is developed in Kazakhstan exploiting data from the geoinformation technologies and using codling moth as a model pest in apples. The basic methodology involved operational thermal map retrieving based on MODIS land surface temperature products and weather stations data, their recalculation into accumulated degree days maps and then into maps of the phases of the codling moth population dynamics. The validation of the predicted dates of the development stages according to the in-situ data gathered in the apple orchards showed a good predictivity of the forecast maps. Predictivity of the prototype can be improved by using daily satellite sensor datasets and their calibration with data received from a network of weather stations installed in the orchards.

Additional keywords: Codling Moth, day degrees, meteorological stations, land surface temperature, plant protection, remote sensing

\section{Introduction}

According to the data of the Ministry of Agriculture of the Republic of Kazakhstan (MoA RK), inadequate implementation of plant protection measures leads to an increase in infestation of agricultural lands by pests, diseases and weeds, resulting in gross harvest losses of 2.2 million tons or 191 million U.S. dollars annually in $80 \%$ of the acreage areas (The Ministry of Agriculture, 2017). Accurate forecasts allow to conduct the most effective actions during the phases of the greatest vulnerability of pests.

Pest forecasting models linking the dynamics of the pest development stages with agro-climatic factors (e.g. accumulated temperature, precipitation) have been devel-

1 St. Petersburg State University, St. Petersburg, 7/9 Universitetskaya nab., St. Petersburg, 199034 Russia.

2 Kazakh Research Institute for Plant Protection and Quarantine named after Zhazken Zhiembayev, Kazakhstan, Almaty, Kazbek-bi, 1.

${ }^{3}$ Russian State Hydrological Institute, V.O. Line 2, 23, St. Petersburg, 199034 Russia.

${ }^{4}$ LLC «NextGIS», Vavilova, 41, office 2, Moscow, 117312 Russia.

* Corresponding author: afonin-biogis@yandex.ru oped over the past century (Zlatanova and Pastukhova, 1975; Riedl et al., 1976; Zlatanova, 1978; Welch et al., 1978; Boldyrev, 1981; Boldyrev, 1991; Knight, 2007; Jones et al., 2013; Drozda and Sagitov, 2017). The usual pest development forecast is based on the data of the closest meteorological stations or according to the interpolated data of meteorological stations which are extremely sparse (the average distance between the nearest meteorological stations in the Republic of Kazakhstan (RK) is more than 100 $\mathrm{km})$. In this regard, farms that are remote from meteorological stations often receive distorted weather information and erroneous forecasts since at a complex terrain the meteorological conditions in the area between weather stations can differ largely for example, the average daily temperatures can vary up to tens of degrees.

Today, remote sensing data (land surface temperature - LST - from satellite sensors) can supplement meteorological data in the intervals between weather stations and make the forecast more precise in space.

However, due to the fact that previously developed methods of agro-climatic forecasts for pest development are based on 
meteorological data, it is necessary to convert the LST data to match the data from weather stations ( $2 \mathrm{~m}$ above the ground). Conversion of such data is widely discussed in the scientific literature, but a uniform approach has not been developed. The majority of studies discuss regional problems of modelling temperatures of surface layer of the atmosphere from space thermal imagery data, focusing on the features of local landscapes (Fu et al., 2011; Benali et al., 2012; Williamson et al, 2014), while in other works algorithms, usually less successful, for recalculations in continental scales (Vancutsem et al., 2010; Shen and Leptoukh, 2011; Meyer et al., 2016) are proposed.

Land surface temperature (LST) is used in studies on argoclimatology and Integrated Pest management (IPM). Sepulcre-Canto et al. (2007) demonstrated the applicability of LST, derived from Airborne Hyperspectral Scanner (AHS) and ASTER satellite, in olive and peach orchards parameters indicating quality. Sona et al. (2012) applied MODIS LST data in order to calculate temperature vegetation dryness index (TVDI) in the Lower Mekong Basin. Raw LST data in this study was used along with Normalized Difference Vegetation Index (NDVI). As already noted, LST is also used in monitoring the risks in agricultural production such as pest's infestation. Lensky, I.M. and U. Dayan (2011) outlined the advantage of MODIS LST data in providing more precise predictions about the timing of Heliothis spp. population expansion in comparasion to weather stations data. LST was used in defining the spatial differences of sweet corn growth and in order to demonstrate the influence of topoclimate on the estimating the dates of the emergence of adult pest from its eclosion. Marques da Silva et al. (2015) studied temporal and spatial distribution of South American tomato moth, Tuta absoluta (Lepidoptera: Gelechiidae) in Portugal comparing LST MSG satellite data and in-situ meteorological data. And revealed a linear regression between Accumulated Degree-Days (ADD) calculated from in-situ and LST data. Blum et al. $(2013 ; 2015)$ compared MODIS LST data and weather stations data for olive grove canopy in the East Mediterranean and claimed LST data to be more accurate than data gathered from meteorological stations and improve the monitoring of the olive fruit fly (Bactrocera oleae) (Diptera: Tephritidae).

Blum et al. (2018) compared MODIS LST data and weather stations data in terms of computing thermal thresholds for cotton bollworm (Helicoverpa armigera), taking also into account parameters such as migration patterns and pesticide use. Yones et al. (2012) used the thermograph and NOAA satellite imagery data in calculating the expected stages of the cotton leafworm Spodoptera littoralis (Boisd.), which were further compared with in-situ data results and produced correction factors to improve the predictability of their model. Blum et al. (2013) built a correction function for LST based on mean differences between LST and in-situ temperatures, included in Fourier series. For areas where in-situ measurements were not available, these parameters were estimated with the use of NDVI data.

Thus, despite the fact that the use of raw LST data shows good forecasting results, conversion of LST to meteorological data is still relevant to the present discussion, because the majority of models for forecasting pest development stages are based on meteorological data. The purpose of this study was the development of a prototype National pest forecasting system in the Republic of Kazakhstan based on exploitation of both LST and meteorological data. In accordance with the intended aim, codling moth IPM forecasting models were adopted in a spatial modeling system using remote sensing temperature data, which should improve the spatial accuracy of the forecasts. The work was conducted within the framework of the Project «GIS forecasting technology for the development of codling moth and apple scab in the southeast of Kazakhstan» during 2015-2017.

\section{Materials and methods}

Our predictive system was designed to define the spatio-temporal development of 
vulnerable stages of the codling moth (Cydia pomonella L.). This prototype system uses average meteorological data from stations and data from the MODIS/Terra sensor of the satellite product MOD11A2.

Study area: The study area is the territory of Southeastern Kazakhstan including more than 600 apple orchards (Figure 1).

Data collection and temperature maps: Temperature maps were made with the use of weather stations' data and data derived from Modis/Terra satellite (MODIS/Terra Land Surface Temperature (LST), 2017). Temperatures from the archive of seven meteorological stations with known coordinates were used for calibration and approximation of the remote sensing data to the stations' data (Bulygina et al., 2018). The MOD11A2 satellite provides an average 8-day, per-pixel, LST data in a $1200 \times 1200$ kilometer grid, spatial resolution $1 \mathrm{~km}$ (Wan et al., 2015).

Phenological model used for ADD calculation:

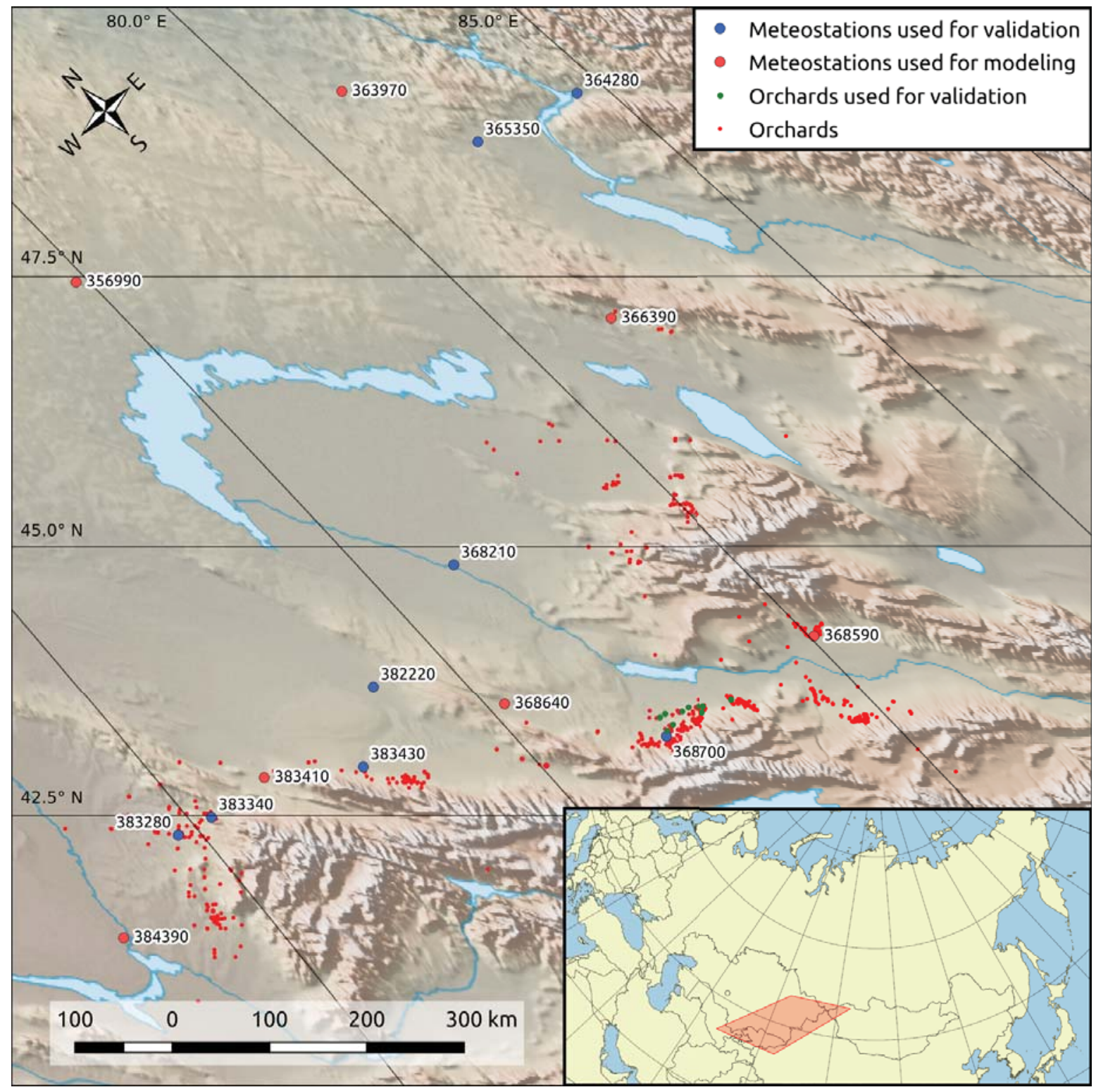

Figure 1. Southeastern territory of Kazakhstan (sinusoidal projection). Numbers on the map show World Meteorological Organization IDs of the stations. 
Calculation of ADD and phenological parameters of codling moth were based on the bioclimatic model by Pralya (2013) (Table 1), in which the lower developmental threshold of the pest is $10^{\circ} \mathrm{C}$. Designed for the orchards of the European territory of Russia, the model of Pralya (2013) predicts the stages of the South Kazakhstan population of the codling moth quite well. Nevertheless, the ADD values for the beginning of flight can vary widely for different geographic populations of the codling moth (Jones et al., 2013). Our observation makes it possible to make an assumption about some displacement of flight start date in the orchards of South Kazakhstan in comparison with the common Pralya model. Therefore, at this stage of the study, $140 \mathrm{ADD}$ (above $10^{\circ} \mathrm{C}$ ) was used as flight start date ADD. In Kazakhstan orchards pheromone traps are not consistently used, so we used dates of transition over 140 ADD as flight start date for the entire territory of the study. These ADD in accordance with the data of the model were used to calculate other dates of the most vulnerable stages of the codling moth and to build maps of phenological dates. The ADDs matrix was calculated using an image calculator module in Idrisi software (Eastman, 2012).

Temperature maps and ADD calculation: Since the average 8-day remote sensing LST data were used, the weather stations' mean daily temperatures were also previously recalculated to the average temperatures for fifteen 8-day periods (from 14 March until 11 July 2017). The average 8-day LST was calculated as the mean temperature measure- ment for night and daytime images ( $\mathrm{LST}_{\text {day; }}$ $\left.\mathrm{LST}_{\text {night }}\right)$. The LST values were taken from the LST maps from the raster cells where seven meteorological stations are located. A generalized regression model for converting LST into weather stations' data was calculated in the Statistica program (Hill and Lewicki, 2007). Then ADD maps were produced with the cumulative total (Figure 2) and ADD maps were recalculated into maps of phenological dates. The modified Pralya model was used to transfer the ADD to phenological dates.

According to the modified Pralya model we have determined the fact that the codling moth's flight start date occurs on the date of transition through the threshold of 140 ADD. The final map of phenological dates was created with the use of raster recalculation. Fifteen 8-day period ADD maps were used as input data. On each of fifteen 8-day period ADD maps we identified pixels, where transition through the threshold of 140 ADD occured for the first time during the relevant 8-day periods. These pixels are highlighted in green in the lower four maps of Figure 3. During the reclassification, the values of Julian dates of the relevant 8-day period, in which the transition through 140 ADD occurs, were assigned to these pixels. Such operation of reclassification was applied to all 15 layers, then these layers were summed up. Thus, after summing the reclassification results, a single raster was obtained, where each pixel contains a date of transition over 140 ADD. This map is presented in Figure 3 (upper map).

Model validation: A two-stage verification of

Table 1. The dependence of the codling moth number dynamic phases from Accumulated Degree Days (ADD) above $10^{\circ} \mathrm{C}$ according to Pralya (2013).

\begin{tabular}{l|c|c|c|c}
\hline \multirow{2}{*}{ Stage } & \multirow{2}{*}{$\begin{array}{c}\text { Codling moth first } \\
\text { flight, \% }\end{array}$} & Larva hatching, \% & 1st generation & 2nd generation \\
\cline { 3 - 5 } & 5 & 0 & $75-120$ & $600-620$ \\
Rmergence & 25 & $1-2$ & $170-190$ & $680-700$ \\
Peak period & 50 & $25-30$ & $260-270$ & $960-980$ \\
Decline in number & 75 & $45-50$ & $370-380$ & $1140-1160$ \\
End of development & 95 & $70-75$ & $480-520$ & $1300-1350$ \\
\hline
\end{tabular}




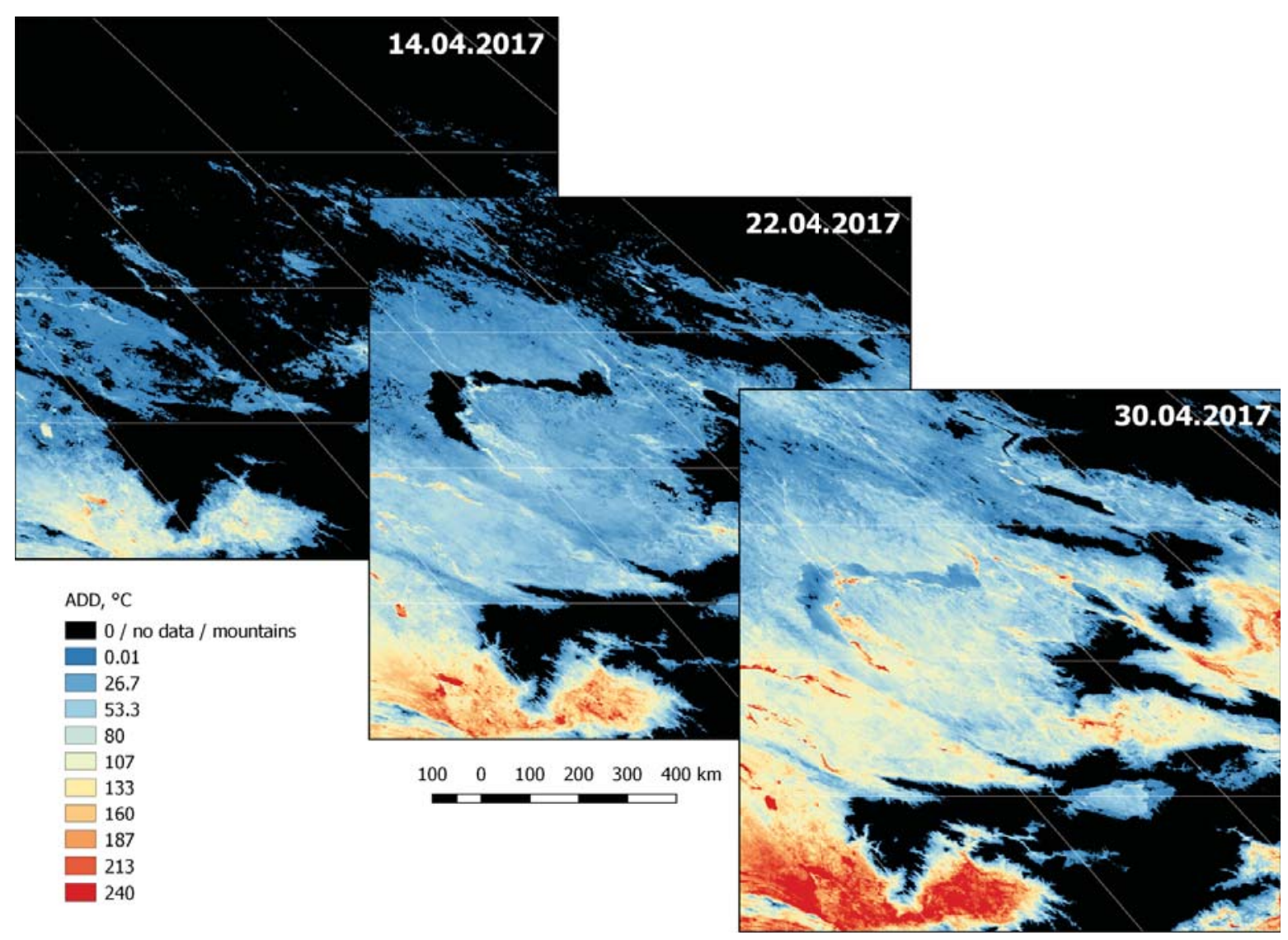

Figure 2. Accumulated degree days above $10^{\circ} \mathrm{C}$ for specific days in 2017 in the region of Southeastern Kazakhstan.

the accuracy of the created maps was carried out. The accuracy of the temperature recalculation of the LST values into meteorological temperature values was checked using data from eight weather stations, other than the seven weather stations where the original data came from. From LST maps and maps of conversion of LST data to meteorological stations data (LST meteo), temperature values were extracted from the raster cells corresponding to the locations of weather stations. Temperature values for similar 8-day periods, calculated from meteorological data $\left(T_{\text {meteo }}\right)$ were taken as the reference values. To validate the model, phenological data which were obtained from apple orchards with pheromone traps were also used.

\section{Results and Discussion}

The relation between temperature and the dates of the development stages of the apple trees as well as the codling moth was calculated from temperature data of the weather stations and LST received from satellite sensors.

The difference in average temperatures, and therefore the ADD, calculated from meteorological and remote sensing data is quite significant. However, the correlation between the temperature values is very high ( $r=0.98-0.99)$, which makes it possible to convert the LST to the values received from weather stations with a high degree of accuracy (Figure 4). In Table 2 for each 8-day period, temperature values averaged across the data of the seven weather stations are presented in 3 variants: 1) average values for meteorological data $\left.\left(T_{\text {meteo}}\right) ; 2\right)$ average values for LST data (raw LST data); 3) average values for LST converted by using a regression model ( $\left.\mathrm{LST}_{\text {meteo}}\right)$.

The following generalized regression formula was derived: $\mathrm{LST}_{\text {meteo }}=4.6+0.056$ 

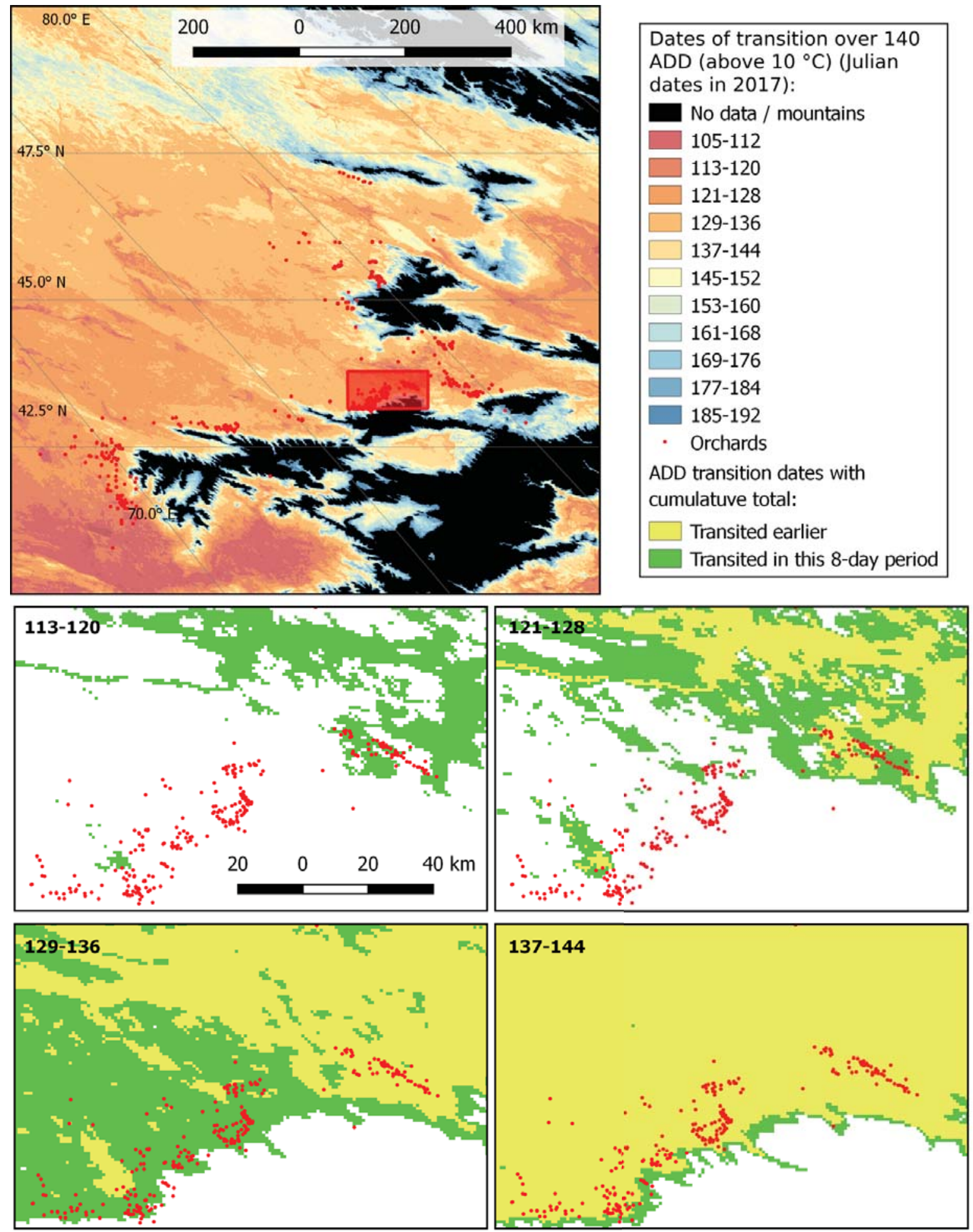

Figure 3. Dates of transition over $140 \mathrm{ADD}$ (above $10^{\circ} \mathrm{C}$ ) (Julian dates in 2017) in Southeastern Kazakhstan and the variant of presentation of codling moth first fligh 8-day prediction. Red dots show the apple orchards location.

$* \mathrm{LST}_{\text {day }}+0.982 * \mathrm{LST}_{\text {night. }}$. Figure 4a shows a comparison between the mean 8-day temperatures on the meteorological data $\left(T_{\text {me- }}\right.$ teo), raw LST data and values calculated by the regression formula ( $\left.\mathrm{LST}_{\text {meteo }}\right)$. The average 8-day temperatures were recalculated into ADD with a threshold value of $10^{\circ} \mathrm{C}$ (Figure $4 b$ ). 

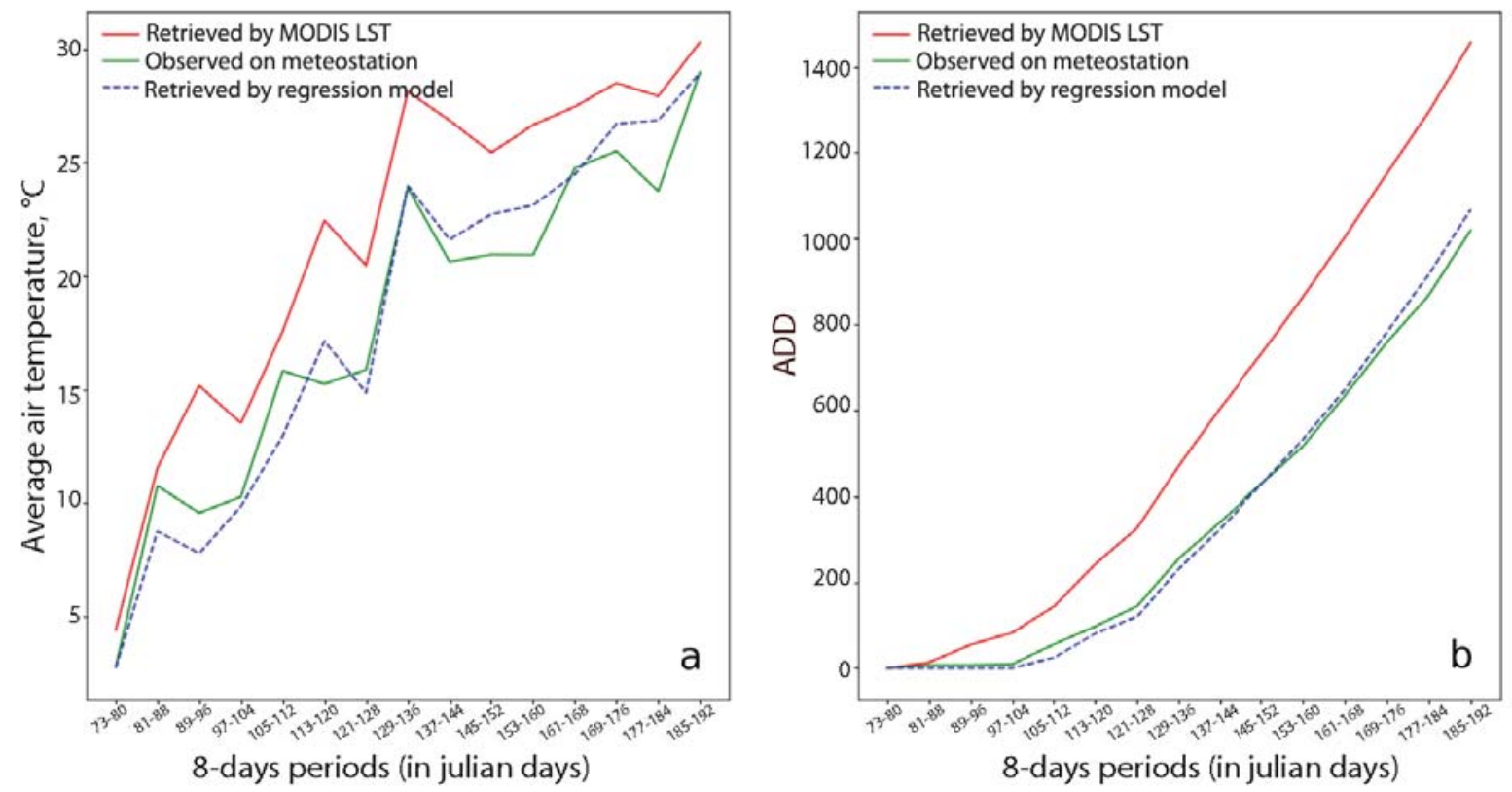

Figure 4. The dynamics of the average temperatures (a) and the ADD (b) calculated from the meteorological data $\left(\mathrm{T}_{\text {meteo }}\right)$, raw LST data and by using regressiom formula (LST meteo) for meteorological station Zharkent (368590).

Table 2. Temperature data, based on meteorological, LST and regression data averaged across the data of seven model weather stations.

\begin{tabular}{|c|c|c|c|}
\hline $\begin{array}{l}\text { Date } \\
\text { (Julian) }\end{array}$ & $\begin{array}{l}\text { Average temperatures calcu- } \\
\text { lated according to weather } \\
\text { stations data }\left(\mathrm{T}_{\text {meteo }}\right),\left({ }^{\circ} \mathrm{C}\right)\end{array}$ & $\begin{array}{l}\text { Average temperatures calcu- } \\
\text { lated according to MODIS LST } \\
\text { data (raw LST data), }\left({ }^{\circ} \mathrm{C}\right)\end{array}$ & $\begin{array}{l}\text { Average temperatures cal- } \\
\text { culated by using regression } \\
\text { models }\left(\mathrm{LST}_{\text {meteo }}\right),\left({ }^{\circ} \mathrm{C}\right)\end{array}$ \\
\hline 2017_073-80 & -2.25 & -0.85 & -1.98 \\
\hline 2017_081-88 & 5.57 & 6.49 & 5.49 \\
\hline 2017_089-96 & 4.37 & 6.94 & 4.84 \\
\hline 2017_097-104 & 9.83 & 11.82 & 8.79 \\
\hline 2017_105-112 & 14.45 & 16.16 & 13.55 \\
\hline 2017_113-120 & 14.30 & 19.77 & 16.00 \\
\hline 2017_121-128 & 14.96 & 18.39 & 14.59 \\
\hline 2017_129-136 & 21.80 & 24.73 & 21.84 \\
\hline 2017_137-144 & 18.70 & 22.56 & 19.05 \\
\hline 2017_145-152 & 20.43 & 23.94 & 19.93 \\
\hline 2017_153-160 & 20.74 & 25.27 & 20.80 \\
\hline 2017_161-168 & 24.12 & 27.58 & 23.99 \\
\hline 2017_169-176 & 26.37 & 29.15 & 26.12 \\
\hline 2017_177-184 & 23.94 & 27.71 & 24.81 \\
\hline 2017_185-192 & 27.88 & 30.91 & 27.48 \\
\hline RMSE & & $3.24^{*}$ & $0.66^{* *}$ \\
\hline
\end{tabular}

* Root Mean Square Error (RMSE) of average temperatures calculated according to weather stations data and average temperatures calculated according to MODIS LST data comparison.

** Root Mean Square Error (RMSE) of average temperatures calculated according to weather stations data and average temperatures calculated by using regression models comparison. 
For each weather station, the differences between $T_{\text {meteo }}$ and raw LST data; $T_{\text {meteo }}$ and $\mathrm{LST}_{\text {meteo }}$ were calculated for the fifteen 8-day periods. For each variant out of 15 differences, RSME (Root Mean Square Error) was calculated. For example, for Kokpekty weather station RMSE by raw LST was 4.69 , and by LST $_{\text {meteo }}$ was 1.20 . The average values of RMSE were: 3.46 for the $T_{\text {meteo }}$ approximation variant by raw LST data, 1.62 by LST $_{\text {me- }}$ teo for model stations, and 1.65 for validating stations (Table 3).

Thus, the use of the regression model in the weather temperature maps made it possible to improve the accuracy of the meteorological temperature approximation significantly in comparasion to raw LST data. The mean values of Root Mean Square Errors (calculated by using regression model to validate stations) are quite equal, allowing the assumption that the recalculation error of conversion LST to $T_{\text {meteo }}$ is approximately $1.7^{\circ} \mathrm{C}$, while the error of using raw
LST data is $3.5^{\circ} \mathrm{C}$.

Conversion of temperature maps based on remote sensing data into maps of weather stations temperature values allowed cartographic forecasts with previously developed methods using weather station data.

The map of the Julian dates of transition through the threshold of 140 ADD, corresponding to the expected dates at the beginning of the spring flight of the codling moth in July 2017 is presented in Figure 3. Phenological maps, in contrast to pheromone traps, allow us to forecast the dates of essential pesticide treatment not only for separate orchards, but for each site (pixel) of the region. This is especially relevant for Kazakhstan due to the fact that monitoring traps are installed only in few orchards.

In the second stage of validation, actual dates of the first spring flight of codling moth, obtained from pheromone traps in 9 orchards in the Almaty region were compared with dates of transition over 140 ADD

Table 3. Accuracy of meteorological temperatures approximation by model and validating stations data.

\begin{tabular}{|c|c|c|c|}
\hline \multirow{2}{*}{$\begin{array}{l}\text { Name of the station } \\
\text { (WMO ID) }\end{array}$} & \multicolumn{3}{|c|}{ Accuracy of meteorological temperatures approximation (RMSE) } \\
\hline & By LST meteo $^{*}$ & By LST meteo ${ }^{* *}$ & By raw LST data *** \\
\hline Bektauata (356990) & 1.10 & - & 2.24 \\
\hline Zhangiztobe (363970) & 1.63 & - & 5.50 \\
\hline Bolshe Narymskoe (364280) & - & 1.51 & 2.84 \\
\hline Kokpekty (365350) & - & 1.20 & 4.69 \\
\hline Urdzhar (366390) & 1.10 & - & 3.63 \\
\hline Bakanas (368210) & - & 1.96 & 2.94 \\
\hline Zharkent (368590) & 1.64 & - & 4.22 \\
\hline Otar $(368640)$ & 1.33 & - & 4.11 \\
\hline Almaty (368700) & - & 2.52 & 3.89 \\
\hline Tole bi (382220) & - & 0.89 & 3.18 \\
\hline Shymkent (383280) & - & 1.99 & 2.19 \\
\hline Aul Turara Ryskulov (383340) & - & 1.43 & 3.10 \\
\hline Taraz (383410) & 1.78 & - & 3.69 \\
\hline Koolan (383430) & - & 1.68 & 3.42 \\
\hline Cardara (384390) & 2.76 & - & 2.32 \\
\hline Mean Values & 1.62 & 1.65 & 3.46 \\
\hline
\end{tabular}

* Root Mean Square Error of average temperatures calculated according to weather stations data and average temperatures calculated by using regression model comparison (for model stations).

** Root Mean Square Error of average temperatures calculated according to weather stations data and average temperatures calculated by using regression model comparison (for validating stations).

*** Root Mean Square Error of average temperatures calculated according to weather stations data and average temperatures calculated according to MODIS LST data comparison. 
(above $10^{\circ} \mathrm{C}$ ) at the locations of the orchards on the produced maps. Since our phenological maps were 8-day, daily details were achieved by interpolation of the values of the forecasted transition dates into the 8-day interval. The differences between the actual and calculated dates were for different orchards from 0 to 3 days, while the average difference for 9 orchards was 1.7 days (Figure 5).

The validation of the calculated dates of transition over 140 ADD (above $10^{\circ} \mathrm{C}$ ) was also carried out by comparing the dates calculated for 15 studied stations by $T_{\text {meteo, }}$ the dates calculated by raw LST data and the dates calculated by LST meteo (Table 4). Table 4 is devoted to the results of the dates of transition over 140 ADD validation for meteorological stations. It was calculated similarly to validation of actual dates of the first spring flight of codling moth, obtained from pheromone traps in 9 orchards in the Almaty region. The difference is that in this case data of meteorological stations was used to calculate the 140 ADD transition dates and was taken as the reference data. The differences between meteorological and LST transition dates were in average 3.98 days for model stations (seven stations used for building the regression formula) and 4.11 days - for

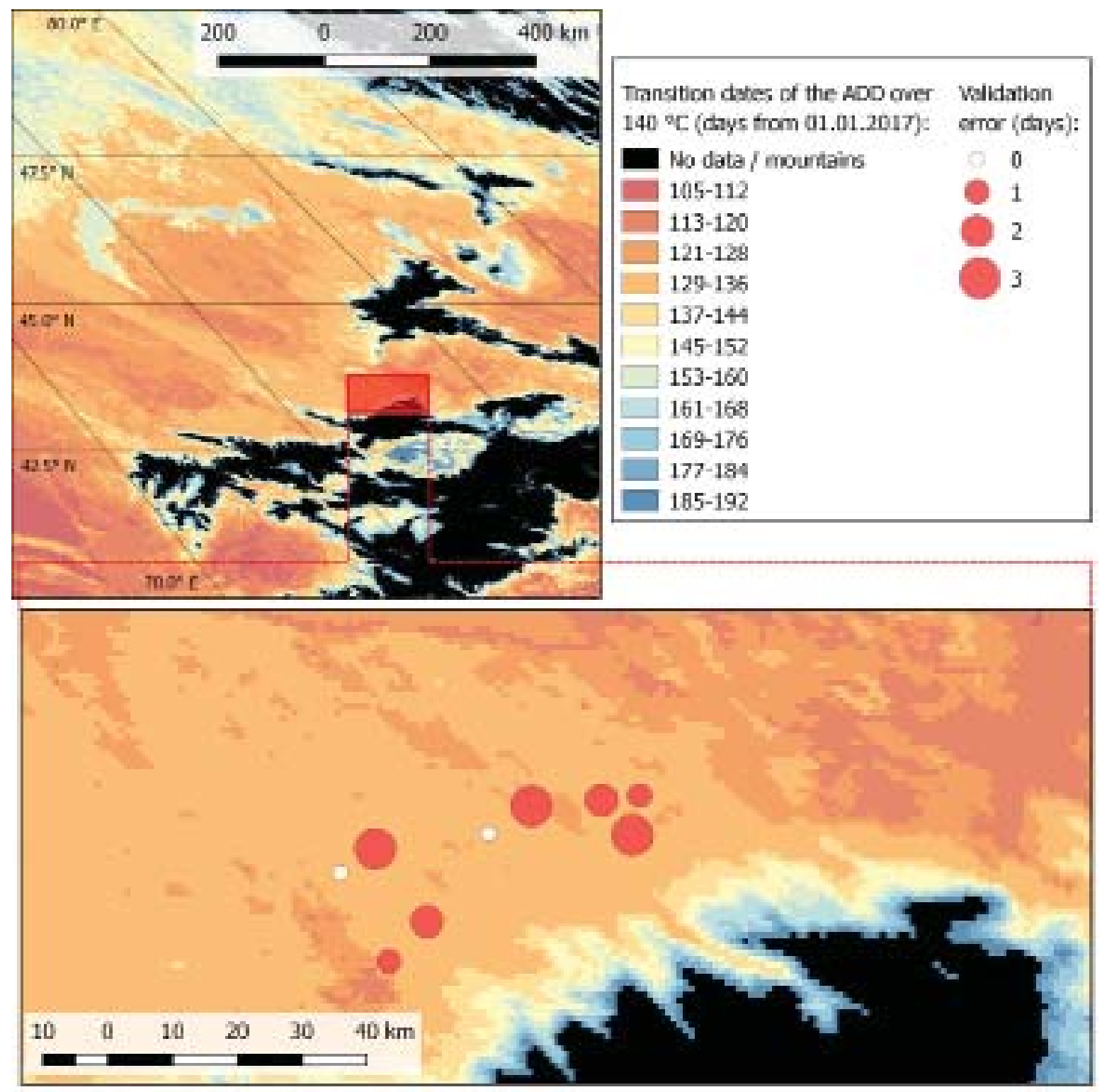

Figure 5. Validation of the expected dates of codling moth first flight by actual data. 
Table 4. Validation of the expected dates of codling moth flight beginning by meteorological data.

\begin{tabular}{l|c|c|c}
\hline \multirow{2}{*}{$\begin{array}{l}\text { Name of the station } \\
\text { (WMO ID) }\end{array}$} & \multicolumn{3}{|c}{$\begin{array}{c}\text { Accuracy of approximation of dates of transition over 140 ADD (above } \\
10^{\circ} \text { C) calculated according to weather stations data (error in days) }\end{array}$} \\
\cline { 2 - 4 } & By raw LST data & $\begin{array}{c}\text { By LST meteo data } \\
\text { (for model stations) }\end{array}$ & $\begin{array}{c}\text { By LST meteo data } \\
\text { (for validating stations) }\end{array}$ \\
\hline Bektauata (356990) & 3 & 2 & - \\
Zhangiztobe (363970) & 18 & 4 & - \\
Bolshe Narymskoe (364280) & 16 & - & -2 \\
Kokpekty (365350) & 17 & - & -2 \\
Urdzhar (366390) & 12 & -3 & - \\
Bakanas (368210) & 10 & - & -3 \\
Zharkent (368590) & 16 & -2 & - \\
Otar (368640) & 13 & - & - \\
Almaty (368700) & 18 & - & 10 \\
Tole bi (382220) & 14 & - & 2 \\
Shymkent (383280) & 10 & - & -3 \\
Aul Turara Ryskulov (383340) & 8 & 7 & 1 \\
Taraz (383410) & 16 & - & - \\
Koolan (383430) & 17 & 5 & 2 \\
Cardara (384390) & 9 & 3.98 & - \\
\hline RMSE & 13.80 & & 4.11 \\
\hline
\end{tabular}

RMSE: Root Mean Square Error.

validating stations (eight stations used for validating the model).

It should be noted that the accumulation of degree days in the orchards lags behind the accumulation on the arid non-irrigated territory, which occupies a significant part of the area of 1 pixel (spatial resolution $1 \times 1 \mathrm{~km}$ ) in the southeast of Kazakhstan. Therefore, in the future, to enable the use of the developled model in the Kazakhstan National system for pest development forecasting in real time, layers of average air temperatures of $1 \mathrm{~km}$ spatial resolution will be created at one day interval. The temperature data received from the temperature sensors of the Modis/Terra will be recalculated into the weather stations' data using the current established calibration regression models. The study territory will be devided into meteorological zones, where each pixel will refer to the area of one weather station and each zone will have its own conversion formula. The layers will be summed up and map of the ADD with a threshold value of $+10^{\circ} \mathrm{C}$ will be updated on a daily basis. The information to the orchards located in these zones will be transmitted by the sms-communication system and through the web GIS interface 1-2 days before the expected starting date of the codling moth's flight. Web GIS interface has already been worked out by Afonin et al. (2016) - http://app.o-gis.org/o-gis/ web/app.php/editor/composition/88.

\section{Conclusions}

The study has shown that remote sensing data can be used as a prospective tool in plant protection by producing phenological maps for forecasting pest development stages. In particular, monitoring of ADD values calculated by Modis data makes possible to predict with sufficient accuracy the timing of the codling moth vulnerable developmental stages and to define optimal dates for farmers to implement pesticide treatment in apple orchards. Further precision 
of forecasts may relate to the refinement of agro-ecological maps e.g. medium resolution satellite images (e.g. Landsat TIRS), forecasts can result in a spatial resolution of $30 \mathrm{~m}$; a meteorological zoning technology and a technology for refined interpolation of under-cloudy data using the original cliche method and separate regression formulas for each zone would also significantly improve the methodological precision of maps (Afonin et al., unpublished).

The reported study was funded by RFBR according to the research project №19-05-00610 and Ministry of Education and Science of the Republic of Kazakhstan.

\section{Literature Cited}

Afonin, A.N., Kazakov, E.E, Milyutina, E.A. unpublished.

Afonin, A.N., Sevryukov, S.Yu., Soloviev, P.A., Luneva, N.N. 2016. Web-GIS for the solution of ecological-geographical analysis and modeling tasks: new opportunities. Vestnik of Saint Petersburg University, Geography and geology, 7(4): 97-111.

Benali, A., Carvalho, A. C., Nunes, J. P., Carvalhais, N. and Santos, A. 2012. Estimating air surface temperature in Portugal using MODIS LST data. Remote Sensing of Environment, 124: 108-121.

Blum M., Lensky, I.M., Nestel, D. 2013. Estimation of olive grove canopy temperature from MODIS thermal imagery is more accurate than interpolation from meteorological stations. Agricultural and Forest Meteorology, 176: 90-93.

Blum, M., Lensky, I.M., Rempoulakis, P., Nestel, D. 2015. Modeling insect population fluctuations with satellite land surface temperature. Ecological Modelling, 311: 39-47.

Blum, M., Nestel, D., Cohen, Y., Goldshtein, E., Helman, D., Lensky, I.M. 2018. Predicting Heliothis (Helicoverpa armigera) pest population dynamics with an age-structured insect population model driven by satellite data. Ecological Modelling, 369: 1-12.

Boldyrev, M.I. 1981. Short-term forecasting of the development of codling moths. Plant protection, 5: 38-39.

Boldyrev, M.I. 1991. Optimal timing and measures to combat the codling moth. Gardening and viticulture, 6: 13-15.

Bulygina, O.N., Razuvaev, V.N., Aleksandrova, T.M. 2018. Description of the data of air daily tem- peratures and precipitation at meteorological stations of Russia and neighboring countries. http://meteo.ru/data/162-temperature-precipitation

Drozda, V.F., Sagitov, A.O. 2017. Evaluation of technologies for protection of apple trees from codling moth. Plant Protection and Quarantine, 5: 1727.

Eastman, J.R. 2012. IDRISI Selva Tutorial, Manual Version 17.0, Clark University. http://uhulag.mendelu.cz/files/pagesdata/eng/gis/idrisi_selva_ tutorial.pdf

Fu, G., Shen, Z., Zhang, X., Shi, P., Zhang, Y. and Wu, J. 2011. Estimating air temperature of an alpine meadow on the Northern Tibetan Plateau using MODIS land surface temperature. Acta Ecologica Sinica, 31(1): 8-13.

Hill, T. and Lewicki, P. 2007. STATISTICS: Methods and Applications. StatSoft,Tusla, OK, 719 p.

Jones, V.P., Hilton, R., Brunner, J.F., Bentley, W.J., Alston, D.G., Barrett, B. et al. 2013. Predicting the emergence of the codling moth, Cydia pomonella (Lepidoptera: Tortricidae), on a degreeday scale in North America. Pest Management Science, 69: 1393-1398.

Knight, A.L. 2007. Adjusting the phenology model of codling moth (Lepidoptera: Tortricidae) in Washington state apple orchards. Environmental Entomology, 36: 1485-1493.

Lensky, I.M. and Dayan, U. 2011. Detection of finescale climatic features from satellites and implications for agricultural planning. Bull. Am. Meteorol. Soc., 92: 1131-1136.

Marques da Silva, J.R., Damásio, C.V., Sousa, A.M.O., Bugalho, L., Pessanha, L., Quaresma P. 2015. Agriculture pest and disease risk maps considering MSG satellite data and land surface temperature. International Journal of Applied Earth $\mathrm{Ob}$ servation and Geoinformation, 38: 40 -50.

Meyer, H., Katurji, M., Appelhans, T., Müller, M.U., Nauss, T., Roudier, P. and Zawar-Reza, P. 2016. Mapping daily air temperature for Antarctica based on MODIS LST. Remote Sensing, 8(9), 732.

MODIS/Terra Land Surface Temperature/Emissivity 8-Day L3 Global 1km SIN Grid V006. 2017. https://lpdaac.usgs.gov/dataset_discovery

Pralya, I.I. 2013. Protection of the apple orchard. AMA-Press, Moscow, 91 p.

Riedl, H., Croft, B.A. and Howitt., A.J. 1976. Forecasting codling moth phenology based on pheromone trap catches and physiological-time models. Canadian Entomologist, 108: 449-460.

Sepulcre-Canto', G., Zarco-Tejada, P.J., Jime'nezMun oz, J.C., Sobrino, J.A., Soriano, M.A., Fereres, E., Vega, V., Pastor, M. 2007. Monitoring yield and fruit quality parameters in open-canopy tree crops under water stress. Implications for ASTER. Remote Sensing of Environment, 107: 455-470. 
Shen, S. and Leptoukh, G.G. 2011. Estimation of surface air temperature over central and eastern Eurasia from MODIS land surface temperature. Environmental Research Letters, 6(4) 045206.

Sona, N.T., Chena, C.F., Chenb, C.R., Changa L.Y., Minh V.Q. 2012. Monitoring agricultural drought in the Lower Mekong Basin using MODIS NDVI and land surface temperature data. International Journal of Applied Earth Observation and Geoinformation, 18: 417-427.

The Ministry of Agriculture of the Republic of Kazakhstan. 2017. http://mgov.kz/en/napravleniya-razvitiya/fitosanitarnaya-bezopasnost/

Vancutsem, C., Ceccato, P., Dinku, T. and Connor, S.J. 2010. Evaluation of MODIS land surface temperature data to estimate air temperature in different ecosystems over Africa. Remote Sensing of Environment, 114(2): 449-465.

Wan, Z., Hook, S., Hulley, G. 2015. MOD11A2 MODIS/ Terra Land Surface Temperature/Emissivity 8-Day L3 Global 1km SIN Grid V006 [Data set]. NASA EOSDIS LP DAAC. doi: 10.5067/MODIS/ MOD11A2.006

Welch, S., Croft, B.A. Brunner, J.F. and Michels, M. 1978. PETE: An extension phenology modeling system for management of multi-species pest complex. Environmental Entomology, 7: 487-
494.

Williamson, S.N., Hik, D.S., Gamon, J.A., Kavanaugh, J.L. and Flowers, G.E. 2014. Estimating temperature fields from MODIS land surface temperature and air temperature observations in a subarctic alpine environment. Remote Sensing, 6(2): 946-963.

Yones, M.S., Arafat, S., Hadid, A.A., Elrahman H.A. and Dahi, H.F. 2012. Determination of the best timing for control application against cotton leaf worm using remote sensing and geographical information techniques. The Egyptian Journal of Remote Sensing and Space Sciences, 15: 151-160.

Zlatanova, A.A. 1978. Forecast of the emergence of individual phases in codling moth development. Proceedings of the Kazakh RIPPQ, 14: 3036.

Zlatanova, A.A., Pastukhova, N.P. 1975. Influence of the photoperiod and temperature on codling moth and microdus development during reactivation. Ekologiya, 5: 82-83.

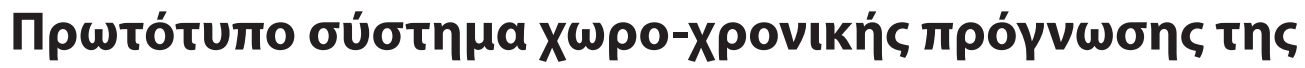

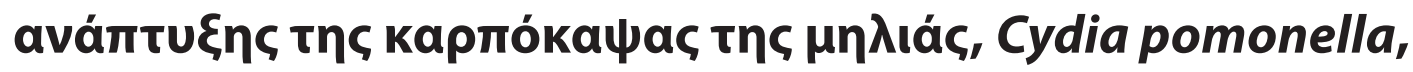 бто Ka〈aкбтáv
}

\author{
A. Afonin, B. Kopzhassarov, E. Milyutina, E. Kazakov, A. Sarbassova kaı A. Seisenova
}

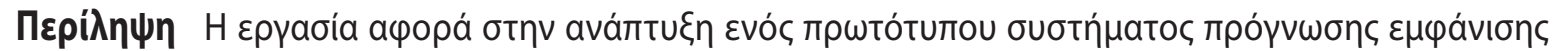

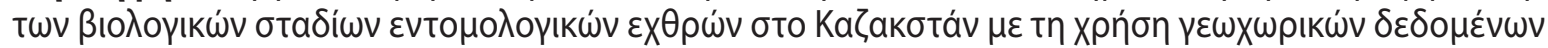

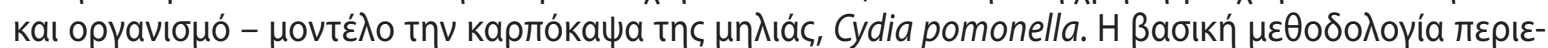

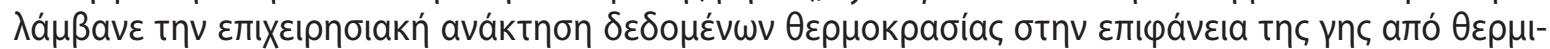

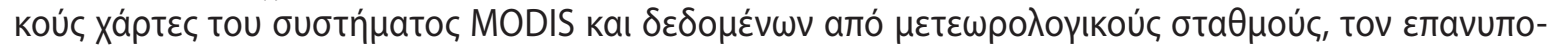

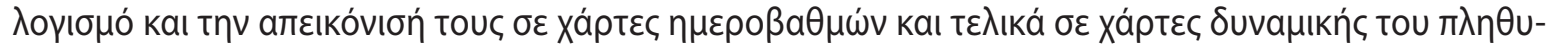

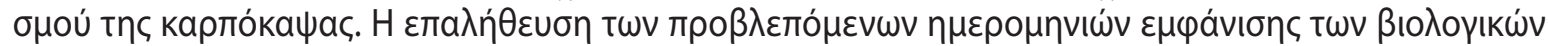

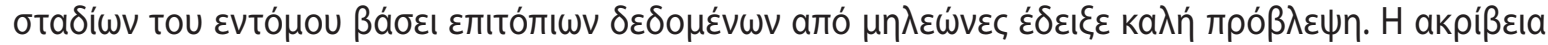

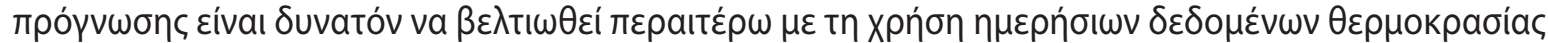

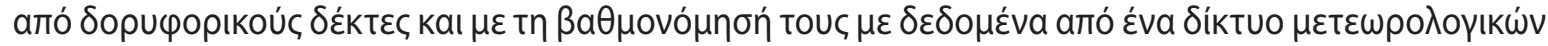

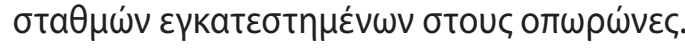

